\title{
The effect of a prestimulus cue on vibrotactile thresholds
}

\author{
DONALD J. FUCCI and HOWARD F. WILSON \\ School of Hearing and Speech Sciences, Ohio University, Athens, Ohio 45701
}

and

\author{
ANN P. CURTIS \\ Department of Communication Disorders, University of New Hampshire, Durham, New Hampshire 03824
}

This study was designed to examine the effect of a prestimulus cue on lingual vibrotactile thresholds. A light was presented as the prestimulus cue to 20 subjects who served as their own control. The thresholds obtained with the prestimulus cue were statistically significantly lower and less variable than the thresholds obtained without the cue.

Obtaining thresholds for sensory stimuli can be considered as consisting of two stages. First, a detection stage would be based upon the physical parameters of the stimulus, such as frequency, intensity, and duration. Second, a decision stage would involve responding to the stimulus based upon a combination of the information from the detection stage and the subject's expectational uncertainty and motivational level. A purely sensory threshold would be the result of a detection process, while a response would involve not only detection but also a decision as to the presence of the signal (Norman, 1963). The present study was designed to study the effect of a prestimulus cue on lingual vibrotactile thresholds.

\section{METHOD}

Twenty subjects were selected from the Ohio University School of Hearing and Speech Sciences. The subjects ranged from 20 to 25 years of age. None of the subjects reported histories of speech, sensory, and/or motor abnormalities.

The equipment used in this study has previously been described in detail by Fucci and Kelly (1972). The stimulus unit consisted of a sine wave generator, an electronic switch-interval timer, an amplifier, a vibrator, a probe, and a contactor. The measurement unit included an accelerometer, a microphone power supply, and a voltmeter. A white-noise generator was used to present auditory masking to subjects through TDH-39 headphones.

The subject was seated in a dental chair and required to extend his tongue between two sterilized plastic disks. A hole in the top disk provided access of the probe to the anterior midline section of the tongue. The tongue was clamped in place tightly enough to hold it, yet not enough to affect normal circulation or cause undue pressure on the structure. The contactor area at the end of the probe was $.128 \mathrm{~cm}^{2}$, with a free surrounding area of $1 \mathrm{~mm}$. To maintain constant pressure of the vibrator on the tongue for all subjects, the probe was lowered until a voltmeter recorded contact. The probe was then lowered $1 \mathrm{~mm}$ further into the tongue surface. The accelerometer was mounted on the

This paper is sponsored by James L. Bruning, who takes full editorial responsibility for its content. probe, which was in turn attached to the electromagnetic vibrator (Fucci \& Kelly, 1972).

Each subject was given a minimum of three practice trials. The subjects were instructed to raise their hand as soon as they detected the stimulus. Thresholds were obtained under two conditions, with the subjects serving as their own control. In the experimental condition, a light was presented as a prestimulus cue before thresholds were obtained, and in the control condition, thresholds were obtained without presentation of the light. Eight thresholds were recorded for each condition. Thresholds were obtained for 10 subjects by first obtaining thresholds with a prestimulus cue and then without it. The order effect was controlled by the reversal of the sequence for the remaining 10 subjects. Lingual vibrotactile thresholds were obtained at $250 \mathrm{~Hz}$ for all subjects, since that is within the range of frequencies to which the tongue is most sensitive (Fucci, Hall, \& Weiner, 1971). All threshold data were converted to microns of displacement using a standard $\mathrm{g}$ formula for acceleration conversion.

\section{RESULTS AND DISCUSSION}

Data in microns of displacement were averaged for the subjects for each of the experimental and control conditions. A statistical analysis for significant differences between the threshold means for both conditions was performed using a $t$ test for dependent means. The mean in microns of displacement for the experimental condition was .859 . For the control condition the mean was 1.016. The t value obtained was 5.707. The critical value for an .01 -level test is $t(.99)=2.539(\mathrm{df}=19)$. The result indicates that the mean threshold for the experimental condition was significantly lower at the .01 level than the mean threshold for the control condition. The significantly lower thresholds obtained in the experimental condition indicate the relative importance of a prestimulus cue in eliciting decreased subjective threshold levels.

The lower thresholds in the experimental condition could be attributed to a variety of factors. The light could have triggered an expectancy set which raised attentional level for the stimulus. An active state of 
attention could increase the focus on the presence or absence of the stimulus. Another factor could be the level of certainty as to the presence of the stimulus. The degree of certainty would increase during a specific time period to the point where a subject would decide to respond. By providing a definite temporal boundary, the light could have reduced the uncertainty as to the presence of a stimulus. Further research is needed in order to clarify the relationship between response variables and their effect upon a subjective threshold level.

\section{REFERENCES}

Fucci, D. J., HAll, D. E., \& Weiner, F. F. Normative study of oral and non-oral structures using vibrotactile stimuli. Perceptual and Motor Skills, 1971, 33, 1099-1105.

Fucci, D. J., \& Kelly, D. H. New instrumentation for research on vibrotactile sensitivity of the tongue. Review of Scientific Instruments, 1972, 43, 1748-1751.

Norman, D. A. Sensory thresholds and response bias. Journal of the Acoustical Society of America, 1963, 35, 1432-1441.

(Received for publication July 16, 1976.) 